\title{
Improvement of Grafted Watermelon Transplant Survival as a Result of Size and Starch Increases Over Time Caused by Rootstock Fatty Alcohol Treatment: Part I
}

\author{
Shawna L. Daley ${ }^{1,3}$, Jeffrey Adelberg ${ }^{2}$, and Richard L. Hassell ${ }^{1}$
}

ADDITIONAL INDEX WORDs. bottle gourd, Cucurbita maxima $\times$ C. moschata, cucurbit grafting, interspecific hybrid squash, Lagenaria sicereria

SUMMARY. Application of fatty alcohol to rootstocks used for vegetable grafting has been shown to increase the efficiency of producing grafted transplants by controlling cucurbit (Cucurbitaceae) rootstock meristematic regrowth and by allowing the rootstocks to accumulate carbohydrates, especially starch, over time in the hypocotyl and cotyledon. A grafting experiment was conducted to determine the effect of increased carbohydrates on survival of watermelon (Citrullus lanatus) grafts using standard grafting procedures. 'Carnivor' interspecific hybrid squash (Cucurbita maxima $\times$ C. moschata) and 'Macis' bottle gourd (Lagenaria sicerevia) rootstocks at $1,7,14$, and 21 days after fatty alcohol treatment were grafted with 'Tri-X 313' seedless watermelon using the one-cotyledon method. Graft survival on 'Macis' rootstock was acceptable or significantly increased up to day 14, with a slight decrease at day 21. Graft survival on 'Carnivor rootstock was also acceptable up to day 21 , with a significant increase between days 1 and 7 . The second experiment was conducted to determine whether the increased carbohydrates provide sufficient energy to successfully graft without the rootstock cotyledon, a method that has previously shown inconsistent results. Graft survival was improved by $90 \%$ using treated 'Carnivor' rootstock 7 days after fatty alcohol treatment and 'Macis' rootstock 14 days after fatty alcohol treatment. Adoption of the hypocotyl-only graft method in commercial production may increase efficiency by better using greenhouse space and could decrease disease probability by removing the cotyledons before grafting.

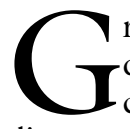
rafting watermelon onto disease-resistant rootstocks can confer resistance to soil borne diseases such as fusarium wilt (Fusarium oxysporum f. sp. niveum) and monosporascus root rot (Monosporascus cannonballus) (Beltran et al., 2008; Guan et al., 2012; Louws et al., 2010). With the loss of methyl bromide as part of the Clean Air Act (U.S. Department of Agriculture, 2012), watermelon grafting is currently the most promising method of fusarium wilt control (Louws et al., 2010). While only $5 \%$ of watermelon acreage in the United States is currently reported to be affected by this disease, arable land for rotation is decreasing and the cost of traveling to

Technical Contribution No. 6261 of the Clemson University Experiment Station.

${ }^{1}$ Department of Plant and Environmental Sciences, Clemson University Coastal Research and Education Center, 2700 Savannah Highway, Charleston, SC 29414

${ }^{2}$ School of Agricultural, Forest, and Environmental Sciences, Clemson University, 275 Poole Agricultural Center, Box 340310 Clemson, SC 29634

${ }^{3}$ Corresponding author. E-mail: sdaley@clemson.edu. disease-free soil is difficult for growers to overcome (D. Liere, personal communication). Although the demand for commercially produced grafted plants is apparent, high production cost remains a major impediment to grafted transplant adoption in U.S. production.

The two most common commercially used grafting methods (over $90 \%)$ are the hole-insertion and the one-cotyledon method (Hassell et al., 2008). These methods require at least one cotyledon to remain intact to ensure graft success (Hassell et al., 2008), and both require manual meristem removal with a blade during grafting and even before transplanting of grafted plants. Manual meristem removal often removes the meristem only partially, allowing meristem regeneration to occur. Previous studies have demonstrated the success of fatty alcohol rootstock treatments in controlling meristematic regrowth (Daley and Hassell, 2014). Fatty alcohol products are traditionally used in tobacco (Nicotiana tabacum) production to remove axillary meristems and promote growth of remaining leaves. When fatty alcohol products are applied to rootstocks used for grafting watermelon, the rootstock meristematic tissue is destroyed and the rootstocks remain viable for grafting (Daley and Hassell, 2014).

In addition to regrowth control, rootstocks treated with fatty alcohol continue to live and photosynthesize, as the cotyledons are also functional leaves (Bisognin et al., 2005). Rather than putting energy into new growth, carbohydrates are stored in the hypocotyl and cotyledons of the rootstocks. Previous experiments have revealed a starch increase of 100and 200-fold in hypocotyls of bottle gourd and interspecific hybrid squash rootstocks, respectively, over $21 \mathrm{~d}$ after fatty alcohol treatment (Daley et al., 2014). We hypothesize that this increase of stored energy in the rootstock could be harnessed by the plant to improve current grafting methods by providing sufficient energy to increase graft survival, rootstock rooting, and overall grafted transplant quality. The first experiment outlined in this article was designed to determine the effect of increased rootstock carbohydrate content on graft survival and rootstock rerooting using the onecotyledon grafting method as described by Hassell et al. (2008).

With current grafting methods, at least one cotyledon is left on the rootstock during grafting. Because the rootstock cotyledons are larger than the cotyledons of watermelon seedlings, the rootstocks require an increase in individual tray cell size over standard cell size for grafted watermelon transplant production. This larger cell size is needed to

\begin{tabular}{llll}
\hline $\begin{array}{l}\text { Units } \\
\begin{array}{l}\text { To convert U.S. to SI, } \\
\text { multiply by }\end{array}\end{array}$ & U.S. unit & SI unit & $\begin{array}{l}\text { To convert SI to U.S., } \\
\text { multiply by }\end{array}$ \\
\hline 29,574 & $\mathrm{fl} \mathrm{oz}$ & $\mu \mathrm{L}$ & $3.3814 \times 10^{-5}$ \\
2.54 & inch $(\mathrm{es})$ & $\mathrm{cm}$ & 0.3937 \\
0.0254 & $\mathrm{mil}$ & $\mathrm{mm}$ & 39.3701 \\
28.3495 & $\mathrm{oz}$ & $\mathrm{g}$ & 0.0353 \\
$\left({ }^{\circ} \mathrm{F}-32\right) \div 1.8$ & ${ }^{\circ} \mathrm{F}$ & ${ }^{\circ} \mathrm{C}$ & $\left({ }^{\circ} \mathrm{C} \times 1.8\right)+32$
\end{tabular}


accommodate the rootstock cotyledon when grafting. In addition to requiring a greater cell size, the large rootstock cotyledons can also harbor foliar disease such as powdery mildew [Podosphaera xanthii (Kousik et al., 2008)] that can prevent successful graft healing or infect successfully grafted transplants.

Decreasing the tray cell size and preventing the spread of disease via the rootstock cotyledon is an important objective in improving the efficiency of grafted transplant production. The development of a successful grafting method that removes both cotyledons would be advantageous to commercial production; however, results of previous studies on this type of method proved to be rather inconsistent for commercial application (Memmott, 2010). Because the cotyledon has been shown to provide energy to the developing rootstock seedling (Bisognin et al., 2005), we hypothesize that the inconsistencies in previous attempts to graft without the cotyledons were a result of a lack of energy in the hypocotyl to support the graft healing and rerooting of the transplant. The increased starch reserves in rootstocks treated with fatty alcohol over time may provide the required energy to overcome the reliance on the cotyledon and make grafting to the rootstock hypocotyl without the cotyledons feasible (Daley et al., 2014). Thus, a second experiment was conducted to test this hypothesis and demonstrate the effect of rootstock age after fatty alcohol treatment on graft survival and rootstock rerooting using the hypocotylonly grafting method.

\section{Materials and methods}

EXPERIMENT 1. The first experiment consisted of two rootstocks: 'Macis' bottle gourd (Nunhems, Parma, ID) and 'Carnivor' interspecific hybrid squash (Syngenta Seeds, Boise, ID). When the cotyledons had unfolded but not expanded $(\approx 6-8 \mathrm{~d}$ and 8-10 d after seeding for 'Carnivor' and 'Macis' rootstock, respectively), seedlings were individually treated with $20 \mu \mathrm{L} 6.25 \%$ fatty alcohol (Fair 85; Fair Products, Cary, NC) applied to the apical meristem of the rootstock seedling, as described by Daley and Hassell (2014). Rootstocks were held in the greenhouse for $1,7,14$, or $21 \mathrm{~d}$ after treatment (DAT) before grafting. Rootstock seeding and treatment dates were scheduled weekly such that grafting for all treatments occurred on the same date. 'Tri-X 313' seedless watermelon (Syngenta Seeds) was used as scion, and seeds were sown, following growing procedures outlined by Hassell and Schultheis (2002), on the same day as the 14-d rootstocks. This timing ensured that the scion age (2 weeks after seeding) was the same for all treatments, with the appropriate hypocotyl size to match the rootstock during grafting. Each rootstock treatment consisted of 10 plants and was replicated four times. The entire experiment was repeated twice, with grafting occurring in April and July 2013. Grafting was performed using the one-cotyledon method as described by Hassell et al. (2008). Because roots require energy to maintain and continue growth (Esau, 1953), rootstock roots were removed during grafting to maintain energy reserves. After grafting, transplants were rerooted in soilless mix.

Experiment 2. The second experiment also used both 'Macis' and 'Carnivor' rootstock cultivars, which were treated with fatty alcohol in the same manner as Expt. 1. Before grafting, all rootstocks remained in the greenhouse for $1,7,14$, or 21 DAT. Rootstocks were sequentially seeded to provide rootstocks of each time after fatty alcohol treatment to graft on the same day. An additional rootstock treatment was also seeded on the same day as the 1 DAT rootstocks, omitting the fatty alcohol treatment to provide an untreated control. 'Tri-X 313 ' seedless watermelon was also used as scion material and was sown to ensure that scion was the same age for each treatment. Each rootstock treatment consisted of 12 plants and was replicated five times. The entire experiment was repeated twice, with grafting occurring in October and Dec. 2013. Grafting was performed using the hypocotyl-only method, consisting of removing both cotyledons from the hypocotyl, making a $30^{\circ}$ angled cut down the side of the hypocotyl and securing the scion to the hypocotyl using a silicone grafting clip (HydroGardens, CO Springs, CO). Rootstock hypocotyls roots were removed in the same manner as Expt. 1 to conserve hypocotyl energy (Esau, 1953).

Growing CONDITIONS. Rootstock seeds were sown in 72-cell plug trays with a l-inch diameter (TLC Polyform, Minneapolis, MN) using a nutrient-free, soilless mix $(75 \%$ sphagnum peat, $25 \%$ perlite; Sun Gro Horticulture, Agawam, MA). Seeds were sown following standard greenhouse production practices (Rutledge, 2009). Scion seeds were sown according to guidelines outlined by Hassell and Schultheis (2002). All seedlings were grown in a standard, doublelayer polyethylene greenhouse covered with a double layer of 6-mil clear plastic (K50 Clear; Klerks Hyplast, Chester, SC). The greenhouse contained a gas heating system to supply heat and exhaust fans to remove heat. Minimum temperatures were set at $60{ }^{\circ} \mathrm{F}$ and the exhaust fans were set to power on when greenhouse temperatures reached $70^{\circ} \mathrm{F}$.

Data collection. All grafted plants remained in the healing chamber for $7 \mathrm{~d}$ following grafting, with relative humidity remaining at $100 \%$ for the first $3 \mathrm{~d}$ and decreasing by $10 \%$ for each of the following $3 \mathrm{~d}$ until relative humidity reached $60 \%$. Relative humidity remained at $60 \%$ throughout day 7 , at which time the plants were removed to the greenhouse for a final week of growth and development. Healing chamber was a $36 \times 122$-inch wooden tray enclosed with 6-mil plastic on hoop frames. A duct-mount centrifugal atomizer humidifier (707U; Herrmidifier, Sanford, NC) was used to maintain humidity in the healing chamber. At the end of the final week in the greenhouse, graft survival data were recorded. Healed transplants that had rerooted successfully (i.e., root balls were adequately developed to prevent smooth removal of the hypocotyl from the tray) were considered surviving transplants. The mix was washed from the roots, which were then separated from the hypocotyl and weighed using an analytical scale (Sartorius A 120 S; Data Weighing Systems, Elk Grove, IL). Root tissue was dried for $5-7 \mathrm{~d}$ at $21{ }^{\circ} \mathrm{C}(320-6$ 1000 Series; Napco Industrial Partner, Richardson, TX). Tissues were individually weighed to determine root dry weight.

Data Analysis. For both experiments, a randomized complete block design was used, with replication as the blocking factor. Graft survival and root fresh and dry weights were analyzed with a linear mixed model using the fit model platform of JMP Pro 
Table 1. Analysis of variance analysis of the effects of rootstock age after fatty alcohol treatment on graft survival and root and root fresh and dry weights of 'Tri-X 313' seedless watermelon grafted using the one-cotyledon grafting method onto two rootstocks: 'Carnivor' interspecific hybrid squash and 'Macis' bottle gourd.

\begin{tabular}{|c|c|c|c|c|c|c|}
\hline \multirow[b]{2}{*}{ Response } & \multirow[b]{2}{*}{ Effect } & \multirow[b]{2}{*}{ df } & \multicolumn{2}{|c|}{ Carnivor } & \multicolumn{2}{|c|}{ Macis } \\
\hline & & & F ratio & $P$ value & F ratio & $P$ value \\
\hline \multirow[t]{2}{*}{ Graft survival $^{\mathrm{z}}$} & Rootstock age ${ }^{y}$ & 3 & 8.8365 & 0.0044 & 43.2486 & $<0.0001$ * \\
\hline & Rootstock age by planting date & 3 & 3.8706 & 0.0490 & 6.3383 & $0.0076^{*}$ \\
\hline Root fresh weight ${ }^{\mathrm{w}}$ & Rootstock age & 3 & 88.4718 & $<0.0001$ & 52.2324 & $<0.0001^{*}$ \\
\hline \multirow[t]{3}{*}{ Root dry weight } & Rootstock age & 3 & 314.6308 & $<0.0001$ & 90.3396 & $<0.0001$ * \\
\hline & Planting date & 1 & 2.6405 & 0.1058 & 12.9713 & $0.0004^{*}$ \\
\hline & Rootstock age by planting date & 3 & 3.6716 & 0.0066 & 17.5340 & $<0.0001^{*}$ \\
\hline
\end{tabular}

${ }^{2}$ Percentage of grafts surviving grafting, healing, and rerooting.

${ }^{y}$ Grafting was performed at $1,7,14$, and $21 \mathrm{~d}$ following rootstock fatty alcohol (Fair 85; Fair Products, Cary, NC) treatment with $20 \mu \mathrm{L}$ ( $0.0007 \mathrm{fl} \mathrm{oz}$ ) $6.25 \%$ emulsion.

${ }^{x}$ Rootstocks were planted in October and Dec. 2013.

"Weights of adventitious roots developed following grafting.

*Values considered significant at $P<0.05$.

$10 \circledR$ software (SAS Institute, Cary, $\mathrm{NC}$ ). The percentage of surviving plants was calculated and used in data analysis. Because the two rootstock types are from separate genera, rootstock data were analyzed separately. The model was a complete factorial model including all combinations and interactions between and among the fixed effects of rootstock age (in DAT) and planting date. Random effects included replication and the interactions among rep and the fixed factors.

\section{Results and discussion Experiment 1}

Analysis OF VARIANCE (ANOVA) ANALYsIs. There were significant effects of rootstock age, as well as some significant effects of planting date and two-way interactions, on graft survival and root growth for rootstocks grafted using the one-cotyledon method (Table 1 ).

Graft survival. Using 'Carnivor' rootstock, we observed no significant differences in graft survival between 1, 7, and 14 DAT (Fig. 1). In both planting dates, there were significant decreases in graft survival at 21 DAT. In past experiments, a similar decrease in rootstock vigor and carbohydrate content was observed in rootstock 21 DAT (Daley and Hassell, 2014), indicating that 'Carnivor' rootstock carbohydrate storage reaches a peak near 14 DAT.

In 'Macis' rootstocks, graft survival increased significantly up to 14 DAT (Fig. 1). However, there were

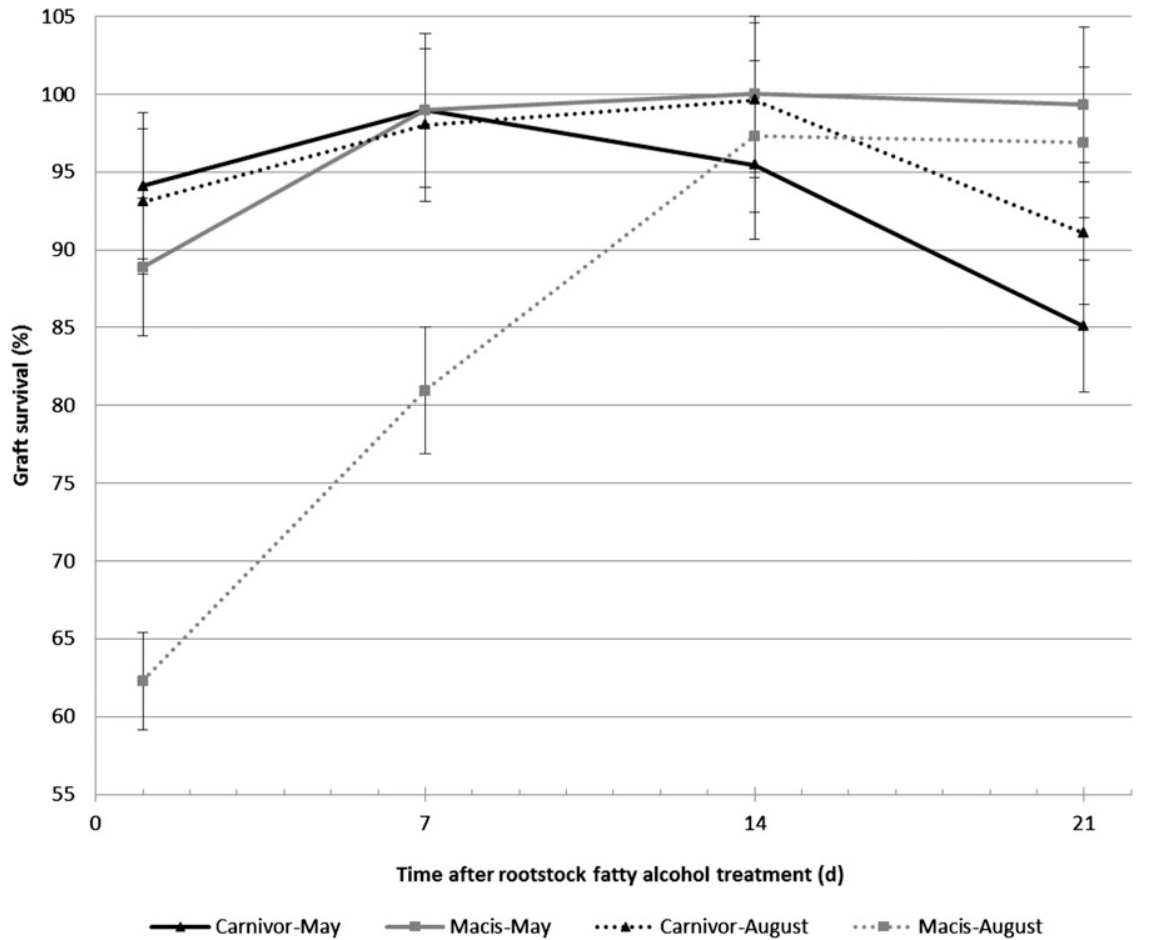

Fig. 1. Graft survival using the one-cotyledon method evaluated as a percent graft healing and rootstock rerooting. 'Carnivor' interspecific hybrid squash and 'Macis' bottle gourd rootstocks were grafted at $1,7,14$, and $21 \mathrm{~d}$ after being individually treated with $20 \mu \mathrm{L}(0.0007 \mathrm{fl} \mathrm{oz})$ of a $6.25 \%$ fatty alcohol emulsion in May 2013 (solid lines) and Aug. 2013 (broken lines).

no significant differences in survival between rootstocks at 14 and 21 DAT, which paralleled a similar pattern of starch accumulation in previous research (Daley et al., 2014). This data indicates that 'Macis' rootstocks are more able to maintain their carbohydrate reserves than 'Carnivor'. The trend of increasing graft survival as time after fatty alcohol treatment progresses illustrates the benefits of the fatty alcohol treatment in improving the efficiency of standard grafting methods by increasing the grafting window of rootstocks from just a few days (Hassell et al., 2008) to at least 2 weeks. 
There was no significant effect of planting date on graft survival in 'Carnivor' rootstock, but we observed significantly lower graft survival in the August planting of 'Macis' rootstock (Fig. 1). Lagenaria rootstock is, in our experience, a more variable rootstock that is sensitive to excessive moisture. The decreased grafting success observed on 1 and 7 DAT in the August planting may be due to the increased amount of watering that occurred within the greenhouse to maintain live plants.

Rootstock RERooting. There was no effect of DAT observed in 'Carnivor' rootstock root fresh and dry weights (Fig. 2). Because the cotyledon remained attached to the rootstock and provided the required energy to heal the grafts and produce new roots, the effect of the increased carbohydrates in the hypocotyl may have been masked in this rootstock. There was a significant DAT effect on root fresh and dry weights in 'Macis' rootstocks. There was a significant increase on 7 DAT in both planting dates (Fig. 2A and B), and no significant differences on 7,14 , and 21 DAT in the May planting. Root fresh weight was significantly lower on 21 DAT in the August planting of 'Macis' rootstocks (Fig. 2A).

\section{Experiment 2}

ANOVA ANALYsIs. There was a significant effect of rootstock age on graft success of both 'Carnivor' and 'Macis' rootstocks, and significant two-way interactions of rootstock age and grafting date on root fresh and dry weights for 'Macis' graft survival. There was also a significant effect of days on root fresh and dry weights of both rootstock cultivars (Table 2).

Graft survival. Using the hypocotyl-only graft, we observed no significant difference in graft survival between the untreated control rootstocks and the treated rootstocks that were 1 DAT with both cultivars, indicating that there was no detrimental effect of the fatty alcohol treatment on graft survival. All cultivars increased significantly in graft success from 1 to 7 DAT, with 'Carnivor' rootstocks increasing to $\approx 90 \%$ survival, and 'Macis' rootstocks increasing to over $45 \%$ and $70 \%$ in the August and December plantings, respectively (Fig. 3). There were no
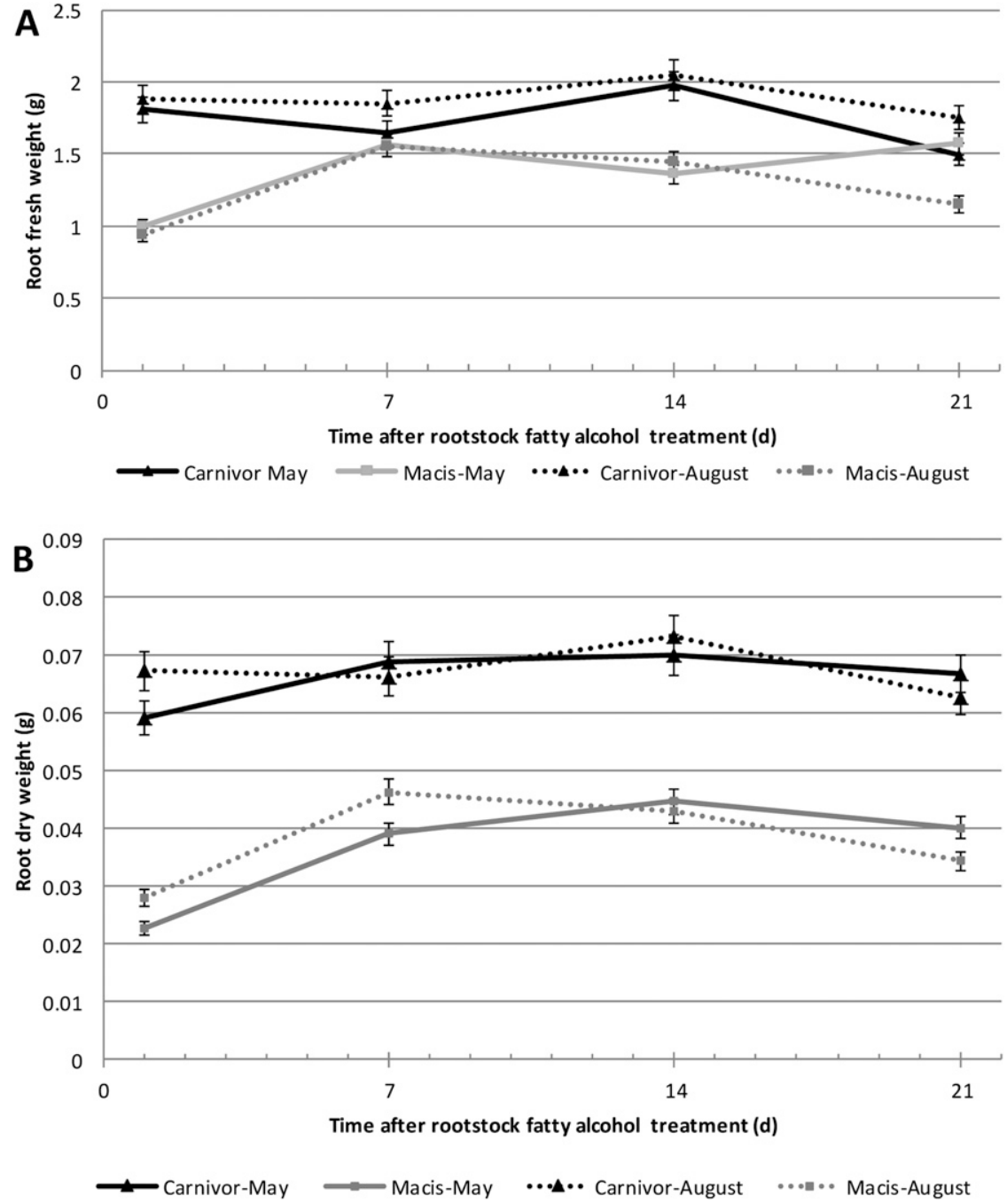

Fig. 2. Adventitious root (A) fresh weight and (B) dry weight of 'Carnivor' interspecific hybrid squash and 'Macis' bottle gourd rootstocks grafted at 1, 7, 14, and $21 \mathrm{~d}$ after fatty alcohol treatment using the one-cotyledon grafting method in May 2013 (solid lines) and Aug. 2013 (broken lines); $1 \mathrm{~g}=\mathbf{0 . 0 3 5 3} \mathrm{oz}$.

significant changes in graft survival for 'Carnivor' rootstocks at 14 and 21 DAT, with the exception of day 21 of the October planting, where graft survival decreased to $\approx 70 \%$. This decrease follows the pattern of starch decrease at 21 DAT in 'Carnivor' rootstocks observed in previous experiments (Daley et al., 2014). 'Macis' rootstock graft survival percentages continued to increase significantly to $\approx 90 \%$ survival at 14 DAT in both planting dates. This also parallels the pattern of starch accumulation observed by the authors (Daley et al., 2014). No significant differences were observed in 'Macis' rootstock between 14 and 21 DAT in the October planting, but survival increased significantly to $98 \%$ at 21 DAT during the December experiment. This pattern of survival indicates that 'Carnivor rootstock increases in graft survival earlier than 'Macis' rootstock.

ROOTSTOCK REROOTING. For both rootstock cultivars, there were no significant differences between the root fresh and dry weights of the untreated control and the rootstocks 1 DAT, indicating that there are no effects of the fatty alcohol treatment on the rootstocks and illustrating the inability of the rootstocks to successfully heal the graft and reroot without taking the time to accumulate energy reserves following the fatty alcohol treatment (Fig. 4A and B). With both 'Carnivor' and 'Macis' rootstocks, we observed a significant increase in root fresh and dry weight at 7 DAT, with the greatest increase observed in 'Carnivor' rootstocks planted in October 
Table 2. Analysis of variance analysis of the effects of rootstock age after fatty alcohol treatment on graft survival and root and root fresh and dry weights of 'Tri-X 313' seedless watermelon grafted using the hypocotyl-only grafting method onto two rootstocks: 'Carnivor' interspecific hybrid squash and 'Macis' bottle gourd.

\begin{tabular}{|c|c|c|c|c|c|c|}
\hline \multirow[b]{2}{*}{ Response } & \multirow[b]{2}{*}{ Effect } & \multirow[b]{2}{*}{ df } & \multicolumn{2}{|c|}{ Carnivor } & \multicolumn{2}{|c|}{ Macis } \\
\hline & & & $F$ ratio & $P$ value & $\mathrm{F}$ ratio & $P$ value \\
\hline \multirow[t]{2}{*}{ Graft survival $^{z}$} & Rootstock age ${ }^{\mathrm{y}}$ & 4 & 294.6396 & $<0.0001^{*}$ & 354.4546 & $<0.0001$ * \\
\hline & Rootstock age by planting date & 4 & 1.6211 & 0.2080 & 3.9440 & 0.0161 * \\
\hline Root fresh weight ${ }^{\mathrm{x}}$ & Rootstock age & 4 & 240.2385 & $<0.0001^{*}$ & 239.1051 & $<0.0001^{*}$ \\
\hline \multirow[t]{3}{*}{ Root dry weight ${ }^{\mathrm{w}}$} & Rootstock age & 4 & 168.5139 & $<0.0001^{*}$ & 213.6674 & $<0.0001$ * \\
\hline & Planting date & 1 & 117.9220 & $<0.0001^{*}$ & 297.0647 & $<0.0001^{*}$ \\
\hline & Rootstock age by planting date & 4 & 20.0910 & $<0.0001^{*}$ & 47.1811 & $<0.0001$ * \\
\hline
\end{tabular}

${ }^{2}$ Percentage of grafts surviving grafting, healing, and rerooting.

${ }^{y}$ Grafting was performed at $1,7,14$, and $21 \mathrm{~d}$ following rootstock fatty alcohol (Fair 85; Fair Products, Cary, NC) treatment with $20 \mu \mathrm{L}(0.0007 \mathrm{fl} \mathrm{oz}) 6.25 \%$ emulsion.

${ }^{x}$ Rootstocks were planted in October and Dec. 2013.

"Weights of adventitious roots developed following grafting.

*Values considered significant at $P<0.05$.

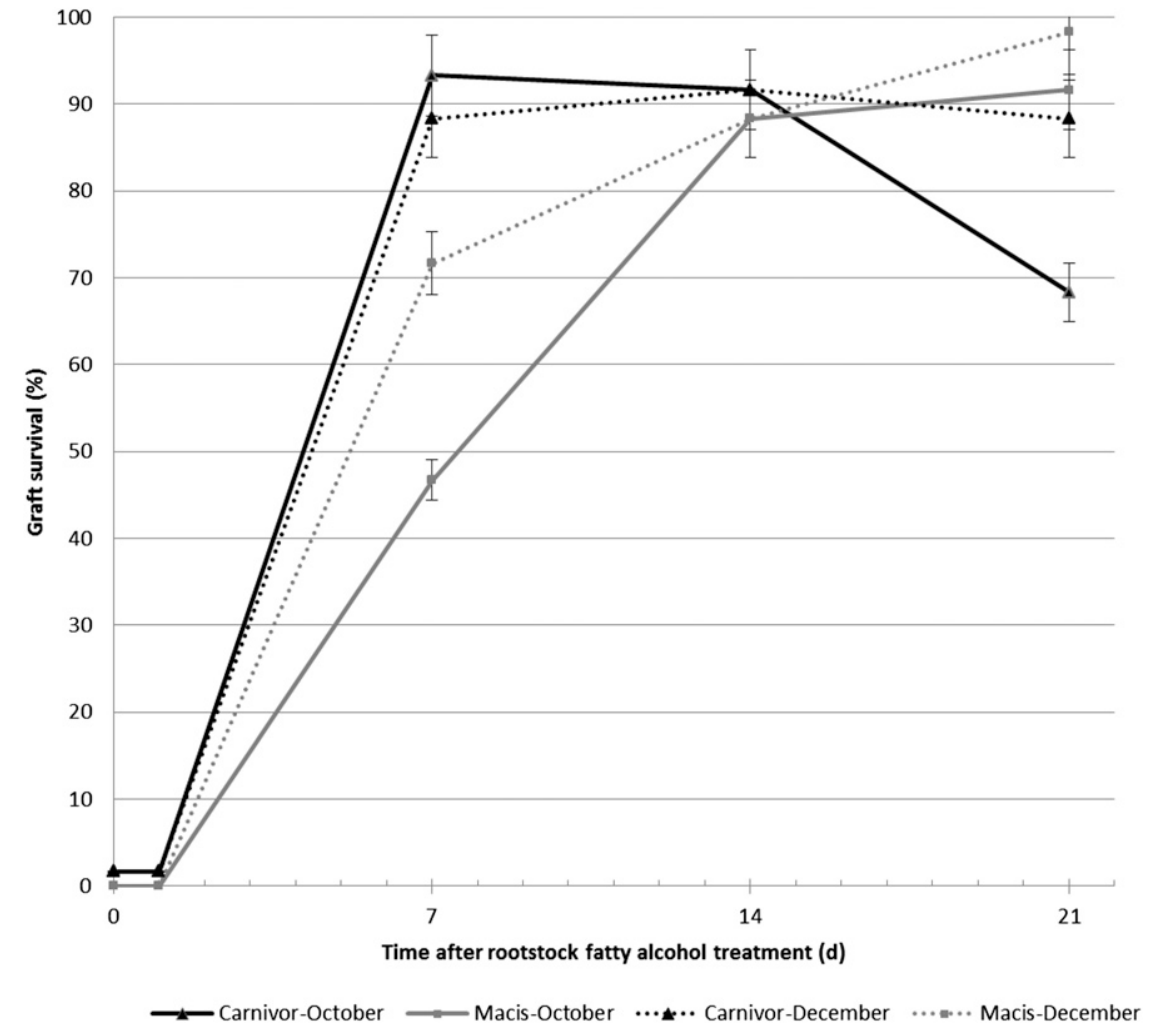

Fig. 3. Graft survival using the hypocotyl-only method evaluated as percent graft healing and rootstock rerooting. Untreated 'Carnivor' interspecific hybrid squash and 'Macis' bottle gourd rootstocks (represented as day 0 ) are used as a control to determine whether deleterious effects of the treatment exist. In addition to the controls, both rootstock types were grafted at ages of $1,7,14$, and $21 \mathrm{~d}$ after fatty alcohol treatment. The experiment was conducted twice in Oct. 2013 (solid lines) and Dec. 2013 (broken lines).

(Fig. 4A and B). 'Macis' rootstocks in the December planting increased the least, from $0.0 \mathrm{~g}$ to nearly $0.2 \mathrm{~g}$ fresh weight at 7 DAT (Fig. 4A). In both cultivars, root fresh weight did not significantly change 7 and 14 DAT, with the exception of 'Macis' rootstocks planted in December In this planting, root fresh weight increased by $0.1 \mathrm{~g}$ at $14 \mathrm{DAT}$. Root fresh weight of 'Carnivor' rootstocks from the October planting increased significantly to nearly $0.9 \mathrm{~g}$ at $21 \mathrm{DAT}$. 'Macis' rootstock from the December planting also significantly increased from $0.3 \mathrm{~g}$ at 14 DAT to almost $0.5 \mathrm{~g}$ at 21 DAT. Both rootstock cultivars produced significantly lower root fresh weights in the December plantings, suggesting that lower temperatures in the winter months decrease rerooting efficiency of both rootstocks.

Similar trends were observed in root dry weights of both cultivars. In each cultivar, there was a significant increase in root dry weight using 7 DAT rootstocks (Fig. 4B). 'Carnivor' rootstocks from the October planting exhibited the greatest increase, reaching $0.08 \mathrm{~g}$ at $7 \mathrm{DAT}$. The least amount of increase 7 DAT was in 'Macis' rootstock from the December planting. Root dry weights of both rootstock cultivars on both planting dates, with the exception of 'Carnivor' in the October planting, also significantly increased at 14 DAT (Fig. 4B). Root dry weights of both 'Macis' and 'Carnivor' rootstocks did not significantly change on 21 DAT in October, but each rootstock cultivar increased significantly on the same day of the December planting. One possible explanation for this was that the more optimal weather in the October planting allowed the rootstocks to reach their peak starch storage by day 14 , but since the weather in December was cooler than optimal, the rootstocks required a greater amount of growing time to accumulate the 

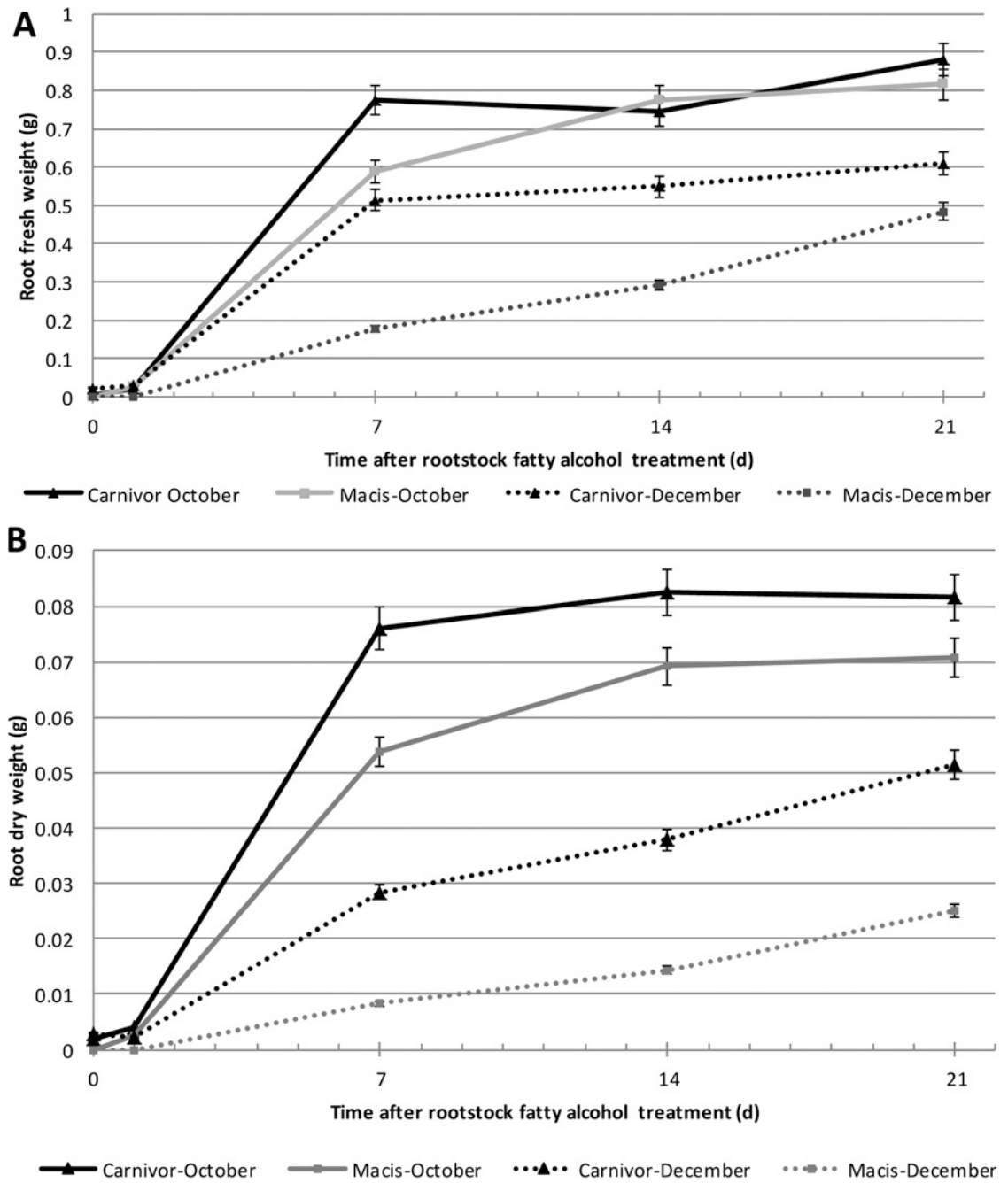

Fig. 4. Adventitious root (A) fresh weight and (B) dry weight of 'Carnivor' interspecific hybrid squash and 'Macis' bottle gourd rootstocks grafted at 0 (untreated), $1,7,14$, and $21 \mathrm{~d}$ of fatty alcohol treatment using the hypocotyl-only grafting method in Oct. 2013 (solid lines) and Dec. 2013 (broken lines); $1 \mathrm{~g}=$ $0.0353 \mathrm{oz}$

required energy and did not have the reserves necessary to produce as much root tissue.

The hypocotyl-only grafting method has not, until now, been successfully performed with consistent success. Based on our data, we conclude that the fatty alcohol treatment overcomes the need for a cotyledon in cucurbit grafting by increasing the amount of energy reserves in the rootstock hypocotyl. After a fatty alcohol treatment, the increased carbohydrate reserves in the rootstock overcome the reliance on the cotyledon to produce energy sufficient for graft survival and rerooting, and make grafting with the hypocotyl possible at 7 DAT for interspecific hybrid rootstocks, or at 14 DAT for bottle gourd rootstocks.

\section{Conclusions}

The physiological differences between the two rootstocks support their differing responses to the fatty alcohol treatment in graft survival. As a hybrid, 'Carnivor' rootstock is typically more vigorous, with a deeper root system, and has recently become a more preferred rootstock in the grafting industry (King et al., 2010). The increased vigor of this rootstock continues to be evident in the rootstock's response to fatty alcohol treatment: compared with bottle gourd rootstocks, 'Carnivor' rootstock requires a greater concentration of fatty alcohol to destroy the meristem (Daley and Hassell, 2014) and also accumulates a greater amount of starch in the hypocotyl (almost 300-fold compared with 30-fold) than 'Macis' rootstocks (Daley et al., 2014). As the rootstocks are from two separate genera within the Cucurbitaceae family and are physiologically different, it is expected that their respective responses to fatty alcohol treatment and performance as rootstocks will differ significantly.

Matching hypocotyl diameter is essential to graft success (Davis et al., 2008). We observed that graft survival decreased at $21 \mathrm{DAT}$ with 'Carnivor' rootstock, possibly because of a cambial mismatch once rootstocks reached that age. 'Carnivor' hypocotyls have previously been shown to double in diameter over 21 DAT (Daley et al., 2014). The difference in hypocotyl diameter between the watermelon scion and the 'Carnivor' rootstock may have prevented graft survival.

Fatty alcohol rootstock treatments can improve success and efficiency of current methods by increasing graft survival and increasing the time period that rootstocks remain suitable for grafting. Grafting in ideal conditions and seasons could further increase the success of the one-cotyledon grafting method. In addition, fatty alcohol treatment allows for successful use of the hypocotylonly grafting method. Removal of the cotyledons with the hypocotyl-only method may decrease chances of disease because the cotyledon could become a harbor for disease as it ages. Complete cotyledon removal also increases production efficiency by decreasing the space requirement of each grafted plant. Doing so will increase the number of grafted plants that can be produced using finite greenhouse spaces, and thus decrease overall cost of production.

\section{Literature cited}

Beltran, R., A. Vicent, J. Garcia-Jimenez, and J. Armengol. 2008. Comparative epidemiology of monosporascus root rot and vine decline in muskmelon, watermelon, and grafted watermelon crops. Plant Dis. 92:158-163.

Bisognin, D.A., L. Velasquez, and I. Widders. 2005. Cucumber seedling dependence on cotyledonary leaves for early growth. Pesquisa Agropecu. Bras. 40:531 539.

Daley, S., W.P. Wechter, and R.L. Hassell. 2014. Improvement of grafted watermelon 
transplant survival as a result of size and starch increases over time caused by rootstock fatty alcohol treatment: Part II. HortTechnology 24:350-354.

Daley, S. and R.L. Hassell. 2014. Fatty alcohol application to control meristematic regrowth in bottle gourd and interspecific hybrid squash rootstocks used for grafting watermelon. HortScience 49:260-264.

Davis, A.R., P. Perkins-Veazie, Y. Sakata, S. Lopez-Galarza, J.V. Marot, S. Lee, Y. Huh, Z. Sun, A. Miguel, S.R. King, R. Cohen, and J. Lee. 2008. Cucurbit grafting. Crit. Rev. Plant Sci. 27:50-74.

Esau, K. 1953. Plant anatomy. Wiley, New York, NY.

Guan, W., X. Zhao, R. Hassell, and J. Thies. 2012. Defense mechanisms involved in disease resistance of grafted vegetables. HortScience 47:164-170.
Hassell, R.L. and J.R. Schultheis. 2002. Seedless watermelon transplant production guide. 27 May 2014. <http:// www.clemson.edu/extension/horticulture/ fruit_vegetable/watermelons/images/ seedless_watermelon_transplant_guide.pdf $>$.

Hassell, R.L., F. Memmott, and D.G. Liere. 2008. Grafting methods for watermelon production. HortScience 43: 1677-1679.

King, S.R., A.R. Davis, X. Zhang, and K. Crosby. 2010. Genetics, breeding and selection of rootstocks for Solanaceae and Cucurbitaceae. Sci. Hort. 127:106111.

Kousik, C.S., A. Levi, K. Ling, and W.P. Wechter. 2008. Potential sources of resistance to cucurbit powdery mildew in U.S. plant introductions of bottle gourd. HortScience 43:1359-1364.
Louws, F.J., C.L. Rivard, and C. Kubota. 2010. Grafting fruiting vegetables to manage soilborne pathogens, foliar pathogens, arthropods and weeds. Sci. Hort. 127:127-146.

Memmott, F.D. 2010. Refinement of innovative watermelon grafting methods with appropriate choice of developmental stage, rootstock genotype, and root treatment to increase grafting success. Clemson Univ., Clemson, SC, MS Thesis.

Rutledge, A.D. 2009. Growing vegetable transplants in Tennessee. 20 Feb. 2013. <https://utextension.tennessee. edu/publications/Documents/PB819. pdf $>$.

U.S. Department of Agriculture. 2012. Crop values 2011 summary. 15 Apr. 2012. <http://usda01.library.cornell.edu/ usda/current/CropValuSu/CropValuSu02-16-2012.pdf>. 